\title{
Advanced AuNMs as nanomedicine's central goals capable of active targeting in both imaging and therapy in biomolecules
}

\author{
Madkour LH* \\ Chemistry Department, Faculty of Science and Arts, Baljarashi, Al Baha University, Baljarashi 65635, Saudi Arabia
}

\section{Introduction}

Au based nanomaterials (AuNMs) are known to possess many attractive features such as unique electrical, optical and catalytic properties as well as excellent biocompatibility. These outstanding characteristics make them promising candidates as the signal reporters, enhancement materials or others involved with bioassay, food safety and environmental monitoring.

Physics, chemistry and biology of Au based nanomaterials (AuNMs) have emerged as a broad and new subdiscipline in the community of colloids and surfaces. The specific size and shape dependent physiochemical properties and remarkable bio/chemical inertness of AuNMs have made themselves the ideal candidates for both fundamental and technical study including crystal growth, electron-transfer mechanism, localized electro-magnetic theory, catalysis, DNA assay, bioimaging and therapy, and so on [1]. Among those rich properties, the optical characteristics originated from the giant electromagnetic field near the surface of AuNMs are particularly intriguing and thus broadly applied in analytical science, e.g. colorimetric assay, surface enhanced Raman spectroscopy (SERS) and surface Plasmon resonance (SPR) spectroscopy, as well as bioimaging. Another interesting optical property of AuNMs is that fluorescence appears with their size shrinkage to below $2 \mathrm{~nm}$, which allows development of luminescence-based analysis. Also, electrochemical (EC) sensors could be constructed based on the redox feature of Au NMs (Figure 1). Analytical science has been playing a primary role in our daily life, for instance, food safety control [2], biomedical diagnosis [3], medicolegal appraisement [4], anti-terrorism alert [5], and environmental pollution monitoring [6]. Efficient detection technologies depend greatly on the analytical method in terms of analysis time, signal-to-noise $(\mathrm{S} / \mathrm{N})$ ratio, selectivity, and limit of detection (LOD) [7]. Therefore, a great of efforts should be paid to develop new analytical methods with the advantages of rapid determination, high analysis flux, satisfactory sensitivity and good robustness. Thanks to the above-mentioned optical and electrochemical features, many functionalized AuNMs have been successfully synthesized [8-13] for improving performances of analytical techniques.

\section{Small organic molecules and metal ions}

For the sensitive detection of small organic molecules, the AuNMs play an important role in improving sensitivity of the EC sensors. Especially, AuNMs composited with conducting polymers or carbon nanomaterials have been used to increase electro-chemical efficiency. It deserves noting that the decorated carbon nanomaterials with metal NPs are of special interest due to the integrated property of two components with better catalytic activity and enhanced electrical conductivity [14,15]. Zhu et al. [16] fabricated EC sensors by using spherical AuNPs combined with conducting polymer (poly-[2, 5-di(2- thienyl)-1H-pyrrole-1-(p-benzoic acid)]). To further improve electron transfer, synergistic effect of multiple nanocomposite layers, namely, chitosan-AuNPs, graphene-AuNPs and multi-walled carbon nanotubes (MWCNTs)-cobalt phthalocyanine, was exploited by Sun et al. [17]. Magalhães et al. [18] fabricated a sensitive and selective EC aptasensor for detection of cocaine based on the conformational change of the aptamer-functionalized AuNPs onto CNTs-based nanocomposite.

Detection of organic small molecules and metal ions is very important for controlling food quality, environmental protection and antiterrorism. In order to realize detection of trace amount of analytes at extremely low concentrations, various efforts for increasing the sensitivity of SPR biosensors have been paid. Most of these methods

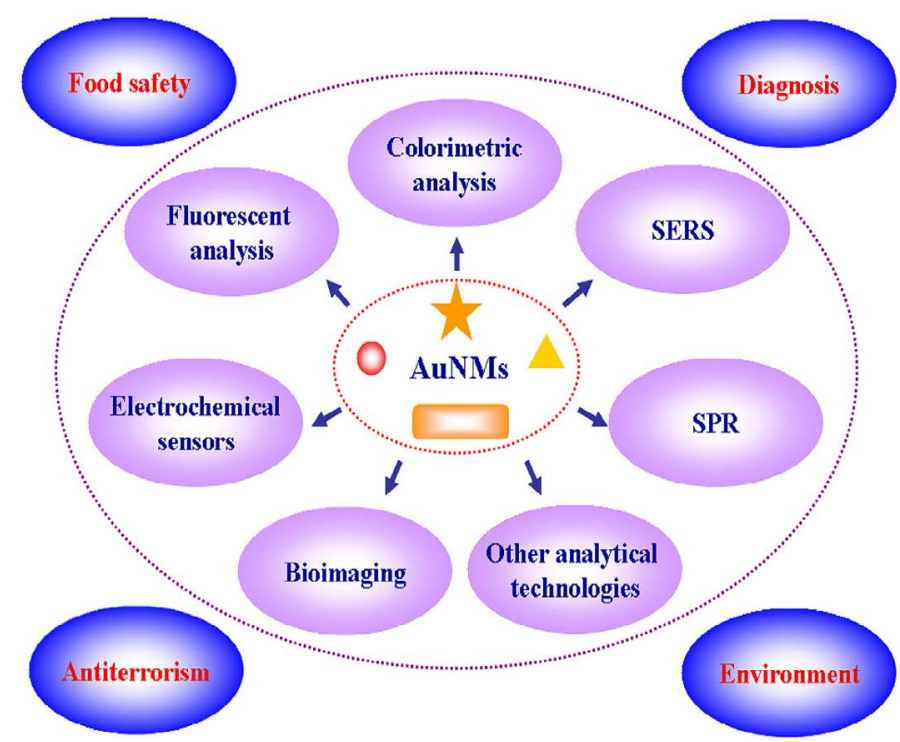

Figure 1. Application of AuNMs in analytical science.

Correspondence to: Madkour LH, Department of Chemistry, Faculty of Science, Baljarashi, Al Baha University, Al Baha, Saudi Arabia, E-mail: loutfy_madkour@ yahoo.com

Received: June 20, 2017; Accepted: July 21, 2017; Published: July 24, 2017 
are based on changing the refractive index at the sensor surfaces by means of a variety of (bio) chemical or NP agents, which are captured by the sensor surfaces subsequent to the binding of the target analyte to the primary biorecognition elements. These methods include the use of secondary and tertiary antibodies, antibodies labeled with enzymes, and dielectric or metallic NPs [19]. In particular, AuNMs of diameters ranging from 5 to $40 \mathrm{~nm}$ have been widely used to enhance the response of SPR biosensors [20,21].

\section{Synthesis of AuNMs}

Traditionally, the trisodium citrate-based thermal reduction has been broadly recognized as a universal approach for preparing spherical Au nanoparticles (AuNPs) of varied sizes ranging from 15 to $147 \mathrm{~nm}$ possessing strong SPR signals [22]. Although this preparation method simply involves controlling the ratios of citrate to Au ions [23], the reaction often needs to be carried out on a relatively large scale at the temperature of boiling water and lacks the reproducible preparation of uniform AuNPs with rather large sizes. After the breakthroughs reported by Schmid [24,25] and Brust et al. [26], a variety of methods have been developed to synthesize AuNMs, and many excellent reviews [27] are available now. In general, the reported synthesis methods of spherical AuNMs can be categorized as followed: (1) citrate reduction; (2) Brust-Schiffrin phase transfer synthesis; (3) other sulfur-containing ligands method; (4) soft templates including micro emulsion, reversed Micelles, surfactants, membranes and polyelectrolytes; (5) seedmediated growth; and (6) physical methods [28]. In addition, nonspherical nanoparticles (NPs) such as Au nanorods (AuNRs) [29], Au nanocages [30], Au cubes [31], Au triangular prisms [32], as well as other unconventional structures like hollow tubes and even branched nanocrystals [33] have attracted significant research attention in the past two decades, since the properties of AuNMs are known to be strongly dependent on the size and shape of the particle [34]. Recently, a lot of excellent reviews have summarized how to achieve shape- and size-defined AuNMs with different techniques including solve thermal synthesis, seed-mediated growth, homogeneous nucleation and electrochemical method $[35,36]$. In this review, we mainly introduce the latest and important advancement of synthesis of the AuNMs, especially on how to control the morphology of AuNMs. A great of efforts have been paid to achieve high-quality and shape-controlled AuNMs for the purpose of highly-sensitive analysis. Unfortunately, most of the synthetic methods are empirical, and understanding their growth mechanism remains a challenging task. Interestingly, introduction of $\mathrm{Ag}^{+}$in growth solutions significantly improves the yield of AuNRs, and Kim et al. [37] prepared AuNRs with controlled aspect ratio by using photochemistry in thepresence of $\mathrm{Ag}^{+}$. This process itself was highly promising for producing uniform AuNRs, and more importantly it was useful indeciphering the growth mechanism of anisotropic AuNPs due to its simplicity and the relatively slow growth rate of the AuNRs. Later, a versatile seed-mediated growth method was reported for selective synthesis of single crystalline rhombic dodecahedral, octahedral, and cubic AuNMs [38]. These results might provide basis for gaining mechanistic insight into the growth of shape-and structure-controlled noble metal nanomaterials. An even more complex sample is nanostar, which is characteristic of uneven arms with different lengths. To fully implement the advantageous property of $\mathrm{Au}$ nanostars, a precise control over their symmetry and uniformity is highly desired. In 2015, Niu et al. [39] obtained Au nanos-tars with excellent symmetry control by using a solution-phase method in high yield and good monodispersity. In their study, icosahedral seeds were used to dictate the growth of the evenly distributed arms in an $\mathrm{I}_{h}$ symmetric manner.
Benefiting from their high symmetry, the Au nanostars exhibited much better single-particle SERS performance compared with asymmetric $\mathrm{Au}$ nanostars, in terms of both intensity and reproducibility. Apart from large-sized Au particles, Au nanoclusters (AuNCs) with the sizes of less than $2 \mathrm{~nm}$ formed in dendrimers displays visible luminescence of high quantum yield (QY) [40]. Ying et al. reported a simple, one-pot and "green" synthetic route, based on the reduction and stabilization capability of bovine serum albumin (BSA) proteins. The AuNCs prepared at the physiological temperature $\left(37^{\circ} \mathrm{C}\right)$ showed red emission with a QY of $\sim 6 \%$ [41]. In order to further control the luminescence property, synthesis of atomically precise AuNCs has ignited numerous research efforts [42,43]. In 2014, Yu et al. [44] synthesized $\mathrm{Au}_{22}$ (glutathione) ${ }_{18}$ clusters of the emission peak at $\sim 665 \mathrm{~nm}$ with a QY of $\sim 8 \%$. Upon comparison of their luminescence properties with those of $\mathrm{Au}$ (I)-thiolate complexes, the enhanced luminescence of $\mathrm{Au}_{22}(\mathrm{SG})_{18}$ was ascribed to aggregation-induced emission. Nevertheless, the origin of emission in AuNCs still keeps unclear, posing a major hurdle for development of highly luminescent clusters. In 2015, Pyo et al. [45] prepared $\mathrm{Au}_{22}$ (glutathione) ${ }_{18}$ clusters with a luminescence QY greater than $60 \%$ by rigidifying their Au shell with tetraoctylammonium cations. This study presents an effective strategy to enhance the luminescence efficiencies of AuNCs by optimizing the shell structure.

In order to precisely tune the size and shape of AuNMs, DNA is recently adopted as a powerful programmable tool to realize above goals. Lu's group systematically summarized morphology controlling, spatial positioning and dynamic assembly of AuNMs with DNA as a powerful tool [46]. In some details, their research results demonstrated that DNA could be used to control the morphologies of AuNMs during seed-mediated growth [47]. They also developed a novel method based on DNA-encoded tuning to achieve AuNMs from AuNR seeds with controlled geometric and plasmonic properties [48]. Furthermore, they suggested that the DNA molecules played important roles via influencing diffusion of the Au precursors to the seed, and therefore the AuNMs growth might be modulated through difference in DNA desorption, density and mobility on the seed surfaces [49]. These insights into the mechanism of DNA-guided AuNMs synthesis not only provide deep understanding of the interactions between the DNA and nanomaterials but also allow better control of the shapes and surface properties of many nanomaterials. Ye et al. [50] designed a millifluidic reactor to synthesize a wide variety of AuNMs at high concentrations. The synthesized method based on millifluidic reactors inspired other researchers to use the analogous reactors for possible mechanism and application study. Recently, Krishna et al. demonstrated adoption of a simple millifluidic chip for in situ analysis of morphology- and dimension-controlled growth of Aunano- and micro-structures with a time resolution of $5 \mathrm{~ms}$ [51] (Figure 2). See from Figure 2, gold structures with $\sim 3 \mu \mathrm{m}$ in diameter that had corrugated metal-like shapes were formed after a time interval of $5 \mathrm{~h}$ (Figure $2 \mathrm{~d}$ ). When the time of flow was increased to $9 \mathrm{~h}$, these structures further transformed into micro-hemispherical ones (Figure 2c). This study offers a feasible way to obtain dimension-and morphology-controlled AuNMs in a high yield.

Noteworthy, some novel synthesis strategies, such as biosynthesis [52,53], 2D immiscible oil/water interface [54], levitated leidenfrost drop [55], sunlight-induced synthesis [56] and so on, have been reported, and such green and economic synthesis methods for preparation of uniform and controlled AuNMs provide the opportunity for development of low-cost and sustainable analytical techniques. However, the above technologies need to be further improved and standardized. 


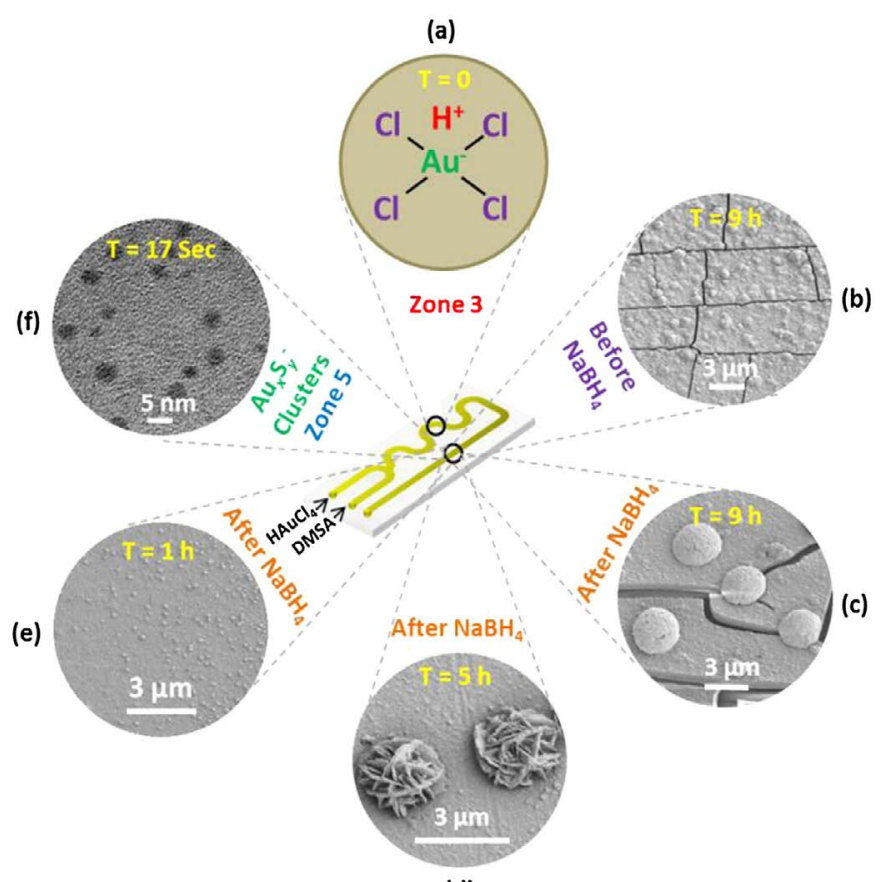

(d)

Figure 2. Scheme showing different stages of spatially (and time) resolved growth process of AuNMs within millifluidic chip. Printed with permission from Krishna et al. [51]. Copyright 2013 American Chemical Society.

\section{Surface modification of AuNMs}

Owing to the large surface to volume ratio, modification and functionalization of AuNMs surfaces with biomolecules, DNA or chemicals becomes imperative for their application in analytical science.

It is well known that free AuNMs have high surface energy and tend to aggregate and fuse. As a result, the intriguing properties observed for the AuNPs would disappear, and the difficulty arises for long term storage, processing, and applications. There-fore, great efforts have been devoted to develop novel strategies to stabilize AuNMs [57], and the most common approach is to coat AuNMs with either organic or inorganic shells. These shells not only endow AuNPs with high stability but also offer them additional functionalities. As an example, in addition to good stability and biocompatibility, the mesoporous silica shells that are currently broadly used have high surface area and tunable pore size and volume, which can accommodate analytes and drug molecules [58].

\section{Biomolecules}

AuNMs have been widely used in SERS based immunoassays of biomolecules such as DNA, protein and cell. However, challenges still remain with amplification of SERS signals due to the extremely small cross-section of Raman scattering [59]. Yan et al. [60] intro-duced a new strategy based on nano rolling-circle amplification (nanoRCA) and nano hyperbranched rolling circle amplification(nanoHRCA) to increase "hot spot" groups for protein microarrays. Li et al. [61] constructed a SERS immune sensor for detection of biomarkers. In their study, the capture antibody was immobilized on the Au triangle nanoarray chip, while the detection antibody was conjugated with the SERS probe (Au@Ramanreporter@SiO ${ }_{2}$ sandwich NP). The antigen (analyte) was sandwiched between the capture antibody and the detection antibody. Under light excitation, a lot of "hot spots" were created between the $\mathrm{Au}$ triangles in nanoarray, and thus the developed SERS immunosensor could be used for sensitive biomarker detection. Luo et al. [62] reported a facile immunoassay for porcine circovirus type 2 (PCV2) based on SERS using multi-branched AuNPs (mb-AuNPs) as substrates. The mb-AuNPs in the immunosensor act as Raman reporters, which were prepared via Tris base-induced reduction and subsequent reaction with $p$-mercaptobenzoic acid. The modified mb-AuNPs were covalently conjugated to the mono-clonal antibody $(\mathrm{McAb})$ against the PCV2 cap protein to form SERS immuno nanoprobes. These were captured in a microtiterplate via an immunoreaction in the presence of target antigens. Compared to conventional detecting methods such as those based on PCR, the method was demonstrated to be rapid, facile and very sensitive. Tang et al. developed a simple and reproducible SERS chip for highly sensitive and selective screening of active ricin in complex matrices [63]. They fabricated single strand oligodeoxynucleotides modified AuNPs in order to amplify recognition and reaction by virtue of their cooperative binding property. To improve sensitivity of this method, a Ag nanoshell was deposited on post-reacted poly (21dA)AuNPs, which lowered LOD to $8.9 \mathrm{ng} \mathrm{mL}^{-1}$.

The utilization of SERS-based techniques in targeting specific DNA and RNA sequences is generally realized by combination with AuNMs and Raman-active molecules $[64,65]$. Wang et al. [66] raised a concept to use enzyme controlled plasmonic coupling as SERS nanosensors for DNA demethylation. The nanosensors were constructed by decorating AuNPs with Raman reporters and hemimethylated DNA probes. The enzymatic degradation of DNA substrate probes was utilized to induce aggregation of AuNPs, so the reproducible and sensitive SERS signals were achieved from biological recognition events. Development of SERS-barcoded particles, which contain multiple Raman-active molecules and are insensitive to photobleaching, is particularly intriguing for high-throughput and multiplex DNA screening [67]. Recently, Chen et al. [68] prepared a SERS-barcoded nanosensor to detect Bacillusthuringiensis $(\mathrm{Bt})$ gene transformed rice expressing insecticidal proteins. The barcoded sensor was designed by encapsulation of AuNPs with silica and conjugation of oligonucleotide strands for targeting DNA strands. The transition between the crylA (b) and $\operatorname{cry} 1 \mathrm{~A}(\mathrm{c})$ fusion gene sequence was used to construct a specific SERS-based detection method with a LOD of $0.1 \mathrm{pg} / \mathrm{mL}$. In order to build the determination models to screen transgene, a series mixture of Bt rice and normal rice were prepared for SERS assay, and the LOD was $0.1 \%(\mathrm{w} / \mathrm{w})$ was explored for transgenic Bt ricerelative to normal rice. The sensitivity and accuracy of the SERS-based assay were comparable with real-time PCR. Recently, Ye et al. [69] proposed an asymmetric signal amplification method for simultaneously detecting multiple biomarkers with significantly different levels. The biobarcode consisted of a large number of signals DNA (Cy3-DNA for Cy3-bio barcode or Rox-DNA for Rox-biobarcode) and capture DNA immobilized onto the Au NPs. The AuNPs simultaneously act both as a Ramansignal-enhancing substrate and a Raman signal carrier. Using these bifunctional probes, a linear amplification mode was obtained with high-concentration markers, whereas quadratic amplification mode was responsible to low-concentration markers.

Detection of circulating tumor cells (CTCs) in the blood of cancer patients is significant for early cancer diagnosis, cancer prognosis, evaluation of the treatment effect of chemotherapy drugs, and choice of cancer treatment options [70]. In 2011, Wang et al. introduced SERS technology for direct detection of target CTCs in human peripheral blood. The LOD of this method ranged from 5 to 50CTCs in $1 \mathrm{~mL}$ of blood [71]. Recently, Wu et al. [72] fabricated SERSNPs for direct detection of CTCs in the blood with excellent specificity 
and high sensitivity. The AuNPs were encoded with a Raman reporter molecule, 4-mercaptobenzoic acid (4-MBA), and then functionalized with reductive bovine serum albumin (rBSA) to stabilize the 4-MBA-encoded AuNPs (AuNP-MBA) and decrease the nonspecific interaction with blood cells. Then AuNP-MBA-rBSA-FA composite NPs were constructed with a targeted ligand folic acid (FA) (Figure $3 \mathrm{~A}$ and $\mathrm{B})$. The FA on the surface of AuNP-MBA-rBSA-FA NPs was recognized by CTCs, which over expressed folate receptor alpha (FRa). The protection layer of rBSA was much thinner than that of the reported PEG, resulting in a stronger SERS signal (Figure 3C).

For detection of the biological macromolecules such as bacteria pathogen and enzyme, SPR with the advantage of label free provides a powerful platform $[73,74]$. There are many successful examples of SPR sensing as a medical diagnostic tool, which have been reported for biomarkers, pathogen detection and hormone analysis with high sensitivity. For example, McPhillips et al. [75] employed aligned Au nanotube arrays to strengthen performance of refractive index sensors in biomolecular binding reactions. Generally, sandwich [76] and competitive or inhibition assay [77] are two major detection approaches in SPR biosensor. In 2012, Fernandez et al. [78] demonstrated that AuNMs combined with sandwich assays could improve detection sensitivity and selectivity of protein detection. Jung et al. [79] introduced a strategy for enhancement of SPR signals by adopting AuNPs and a $\mathrm{SiO}_{2}$ layer on an $\mathrm{Au}$ surface. The modified surfaces showed significant changes in SPR signal when biomolecules were attached to the surface as compared with an unmodified Au surface.

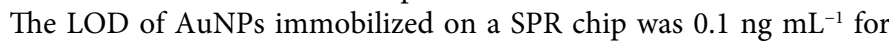
the prostate specific antigen (PSA), a cancer marker. The enhanced shift of the absorption curve resulted from coupling of the surface and particle plasmon by the $\mathrm{SiO}_{2}$ layer and the AuNPs on the gold surface.
Now, there were a lot of reports of SPR sensors based on spherical AuNMs for detection of biomolecules [80,81]. The anti-E.coli O157:H7 polyclonal antibodies (pAb) were labeled with AuNPs, which were used as secondary antibodies. The E.coli O157:H7 was detected using direct assay and enhancing sandwich assay based on the two channels SPR biosensor. By introducing AuNPs-PAb compound, the LOD was determined to be $10 \mathrm{cfu} / \mathrm{mL}$. The sensitivity was 100 times higher than that of direct detection [82]. Compared with spherical AuNMs, AuNRs labels are more favorable for the Au-amplified SPR biosensors because of the tunable longitudinal plasmonic peak enables an effective plasmonic coupling between sensing film and NPs. Law et al. [83] revealed the potential of applying this "perfectly matched" nanotag in a well-established SPR sensing system and immunoassay. Through detection of tumor necrosis factor alpha antigen, 40-fold sensitivity enhancement using wavelength-matched AuNRs was observed. Recently, Xiang et al. [84] developed a SPR DNA biosensor array based on target-primed rolling circle amplification (RCA) for isothermal and rapid detection of two pathogenic mycobacteria, mycobacterium tuberculosis complex (MTBC) and mycobacterium avium complex (MAC) (Figure 4). AuNPs were directly assembled on to the surface of the sensor chip via hexanedithiol (HDT) for enhancement of sensitivity as a label-free detection system. Experimental results showed that the signal enhancement by the target-primed RCA together with AuNPsembedded surface caused at least 10 -fold increased sensitivity as compared with conventional RCA on bare SPR chip method.

Besides, the chemical vapor deposition (CVD) method has been adopsted by Ruoff's group for large scale preparation of high-quality graphene sheets [85]. The strategy based on AuNMs combined with graphene sheets could improve the conductivity of SPR [86]. In 2013, Zhang et al. [87] employed Au-graphene oxide composite in the

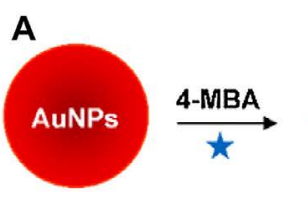

B

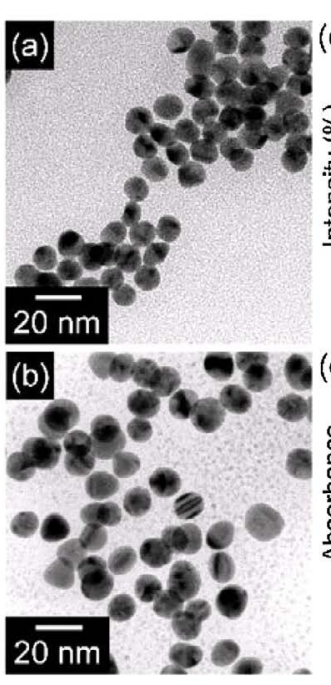

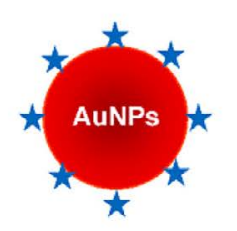
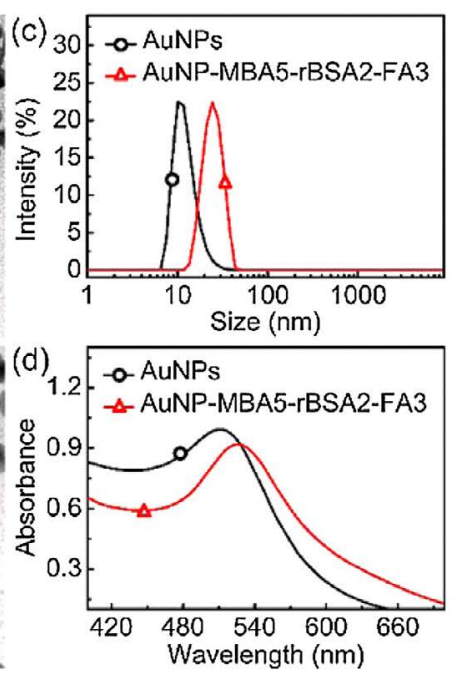

rBSA
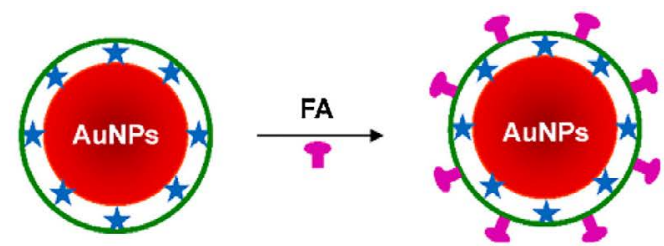

C
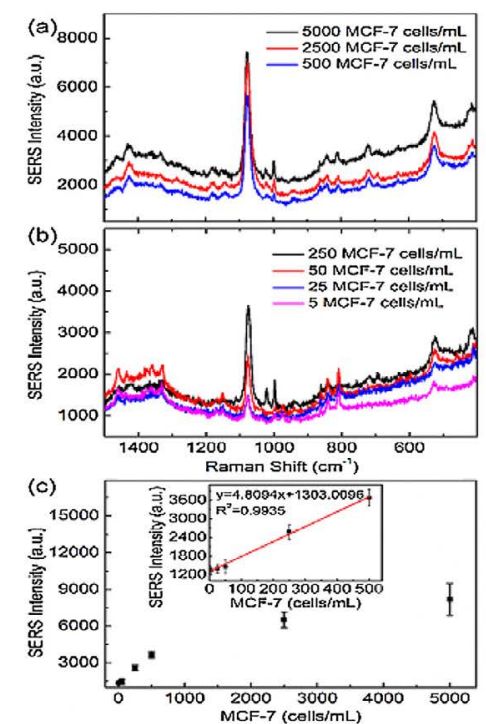

Figure 3. (A) Schematic Illustration for the Design of SERS Nanoparticles. (B) Characterization of the AuNPs (control) and SERS nanoparticles. TEM images of AuNPs (a) andAuNPMBA5-rBSA2-FA3 (b). (c) Size distributions of AuNPs and AuNP-MBA5-rBSA2-FA3 in Milli-Q water at room temperature. (d) UV-vis spectra of AuNPs and AuNP-MBA5-rBSA2-FA3. (C) Detection sensitivity of the AuNP-MBA5-rBSA2-FA3 nanoparticles for MCF-7 cells in the rabbit blood. Printed with permission from Wu et al. [72]. Copyright 2015 American Chemical Society. 
A

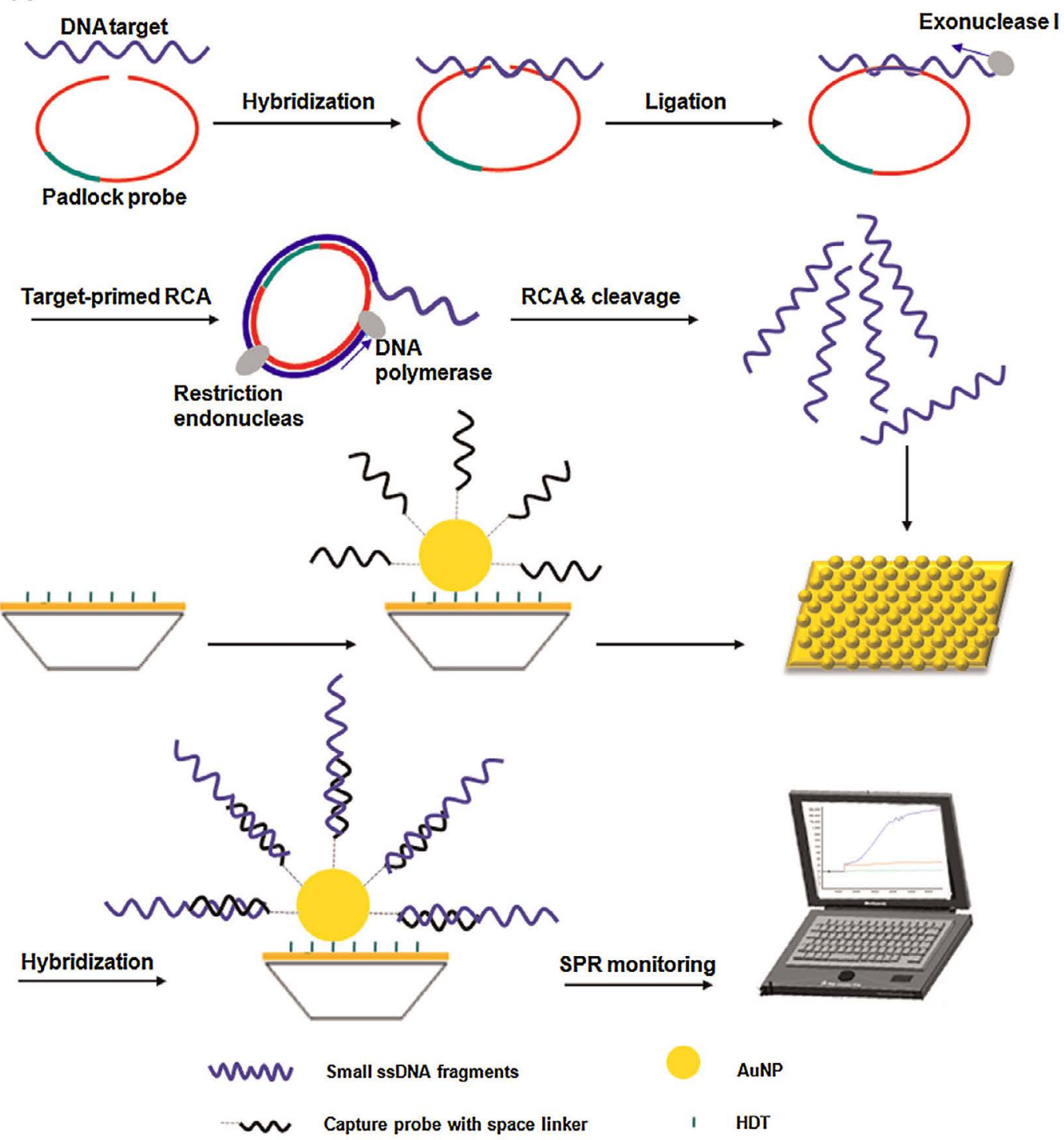

B
5'
$\mathrm{Ta}$
code
$\mathrm{Tb}$

Figure 4. (A) Principle of target-primed RCA-cleavage reaction-based AuNP-embedded SPR assay. (B) Mode of the padlock probe. Ta and Tb are asymmetric target complementary regions in padlock probe. Each padlock probe contains a unique code sequence for multiplex hybridization. The dotted line represents the bases in the linker sequence. Printed with permission from Xiang et al. [84]. Copyright 2015 Elsevier.

wavelength modulation SPR biosensor for rabbit IgG detection. In their study, the staphylococcal protein A (SPA) modified Au-graphene oxide composite was directly immobilized onto SPR chips without any additional chemical treatment. The biosensor with the SPA modified Au-graphene oxide composite as the enhanced sensing platform exhibited a satisfactory response to rabbit IgG. The LOD obtained with the composite was 16 times lower than that obtained with the SPA modified chip. This study provided a simple and effective approach for fabrication of sensitive SPR immunosensors and extended the application of the Au-graphene oxide composite in immunoassays.

Molecularly imprinted polymers (MIPs) have become a competitive tool in the field of molecular recognition, owing to their low cost, physical robustness, thermal stability and easy preparation over biological receptors and other functionalized materials [2]. High surface-to-volume ratio makes AuNPs a competitive candidate as matrix material for novel nanosized MIPs. Xie et al. [88] showed a surface molecular self-assembly strategy for MIP in electro polymerized aminothiophenol (ATP) membranes at the AuNP-modifiedglass carbon electrode for electrochemical detection of pesticidechlorpyrifos. Yu et al. [89] constructed an EC sensor for determination of dopamine based on core-shell composite of AuNPs and $\mathrm{SiO}_{2} \mathrm{MIPs}$ through solgel technique. Similarly, Xue et al. [90] prepared a highly sensitive and selective biomimetic EC sensor for amperometric detection of trace dopamine (DA) in human serums by AuNPs doped MIPs (Figure 5). 


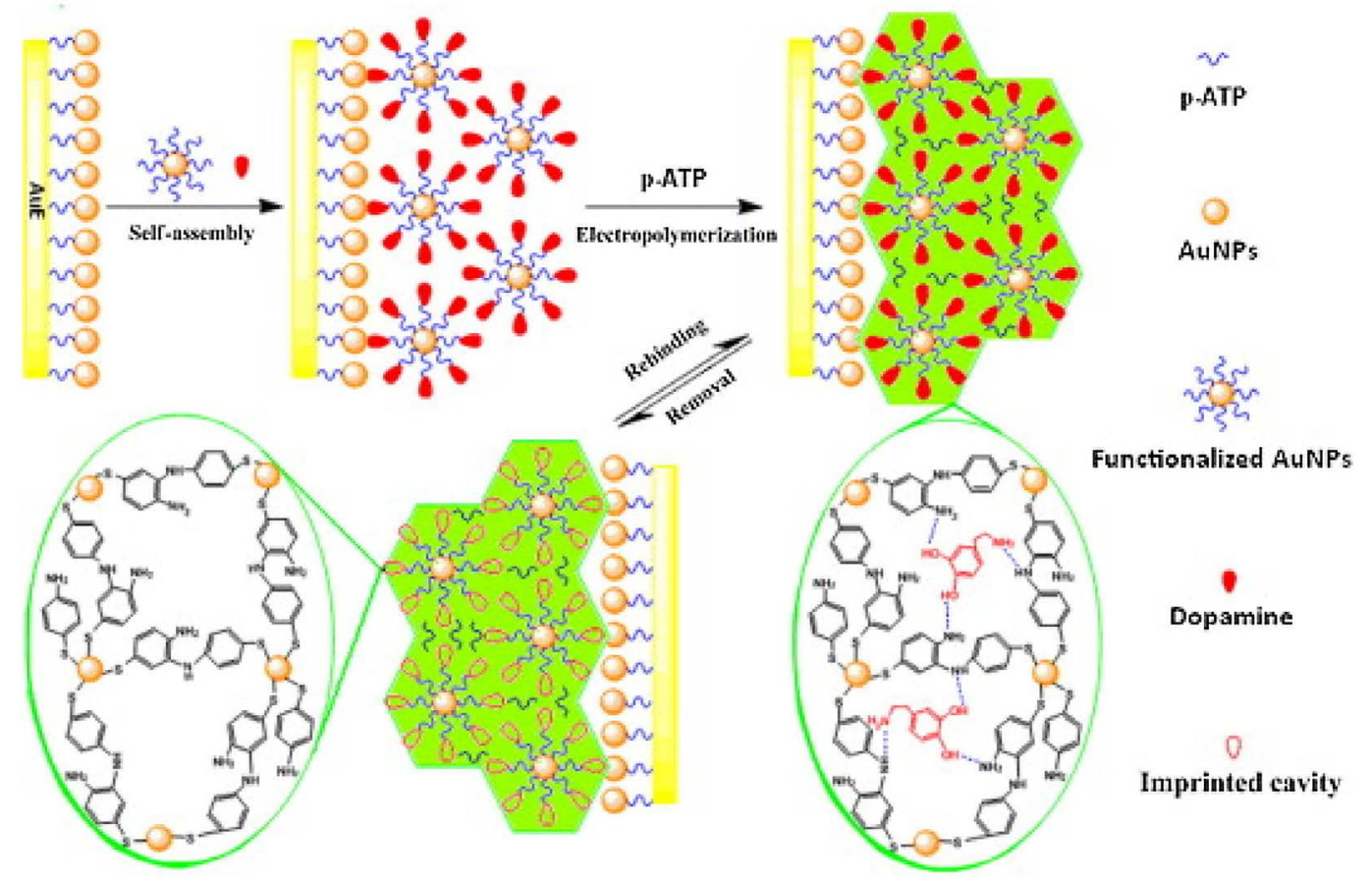

Figure 5. Scheme of preparation of AuNPs@MIES. Printed with permission from Xue et al. [90]. Copyright 2013 Elsevier.

The LOD of the proposed EC sensor for DA was $7.8 \mathrm{n} \mathrm{mol} / \mathrm{L}$. Sun et al. [91] presented an EC sensor for detection of 3-chloro-1,2-propandiol (3-MCPD) that was usually used as surfactant. They fabricated an AuNPs-modified glassy carbon electrode coated with an MIP film via electropolymerization. The LOD reached $3.8 \times 10^{-18} \mathrm{~mol} / \mathrm{L}$. impressively, the sensor showed high sensitivity, good selectivity, excellent reproducibility and stability during the quantitative determination of 3-MCPD.

\section{Metal ions}

Some EC sensor methods based on AuNMs have been developed for detection of heavy metal ions. For examples, Shen et al. [92] proposed an EC DNAzyme sensor based on AuNPs for sensitive and selective detection of $\mathrm{Pb}^{2+}$. A label-free $\mathrm{EC}$ sensor was developed for the highly sensitive and selective detection of $\mathrm{Hg}^{2+}$ by Tang et al. [93]. In their study, the catalytic $\mathrm{HAuCl} 4 / \mathrm{NH}_{2} \mathrm{OH}$ reaction was utilized for formation of AuNPs as signal reporter after capturing $\mathrm{Hg}^{2+}$ on the modified electrode surface through the specific thymine- $\mathrm{Hg}^{2+}$-thymine $\left(\mathrm{T}-\mathrm{Hg}^{2+}-\mathrm{T}\right)$ coordination. Com-pared with the traditional metal NPsbased method, this sensor avoided the labeling of the DNA probe with NP tags, and only one unlabeled T-rich DNA sequence was needed, which greatly reduced the cost and simplified the sensing procedure. Thus, a LOD as low as $0.06 \mathrm{nM}$ could be obtained for $\mathrm{Hg}^{2+}$. Furthermore, in 2016, Wang et al. [94] presented a sensitive, selective and reusable EC biosensor for determination of $\mathrm{Hg}^{2+}$ based on thymine modified AuNPs/reduced graphene oxide nanocomposites (Figure 6). Notably, the developed $\mathrm{EC}$ sensors afforded excellent selectivity for $\mathrm{Hg}^{2+}$ against other heavy metal ions including $\mathrm{Zn}^{2+}, \mathrm{Cd}^{2+}, \mathrm{Pb}^{2+}, \mathrm{Cu}^{2+}, \mathrm{Ni}^{2+}$ and $\mathrm{Co}^{2+}$. Wang et al. [95] prepared an EC sensor based on graphene and AuNPs for detection of trace $\mathrm{Cu}^{2+}$ with the anodic stripping voltammetry analysis. Yang et al. [96] constructed a highly sensitive electrochemical DNA biosensor made of polyaniline (PANI) and AuNPs nanocomposite (AuNPs@PANI) for detection of trace concentration of $\mathrm{Ag}^{+}$. In the presence of $\mathrm{Ag}+$, with interaction of cytosine- $\mathrm{Ag}+-$ cytosine $\left(\mathrm{C}-\mathrm{Ag}^{+}-\mathrm{C}\right)$, cytosine-rich DNA sequence immobilized onto the surface of AuNPs@PANI had a self-hybridization and then formed a duplex-like structure. The prepared EC sensors could detect $\mathrm{Ag}^{+}$at a wide linear range of $0.01-100 \mathrm{nM}$ with a LOD of $10 \mathrm{pM}$.

\section{Biomolecules}

Ultrasensitive detection of biomolecules (especially for disease markers) is very important for early disease diagnosis. To real-ize ultrasensitive detection of biomolecules, development of novel and robust detection methods for signal amplification of EC sensors is essential. In past work, a lot of photo- or electro-active indicators, such as ferrocene [97], methylene blue [98] and enzymes [99], were immobilized onto AuNPs to realize the detection signals amplification. Zheng et al. prepared an ultrasensitive EC sensor based on networklike thiocyanuric acid/AuNPs for detection of thrombin [100]. Zhao et al. [101] fabricated an ultrasensitive and highly specific EC aptasensor for thrombin based on amplification of aptamer-AuNPs-horseradish peroxidase conjugates. He et al. [102] reported a label-free and sensitive signal-on electrochemical assay for MTase quantification and activity analysis using AuNPsamplificatio. In 2016, an ultrasensitive DNA biosensor was developed through in situ labeling of electroactive melamine- $\mathrm{Cu}^{2+}$ complex $\left(\mathrm{Mel}-\mathrm{Cu}^{2+}\right)$ on the end of hairpin-like probe using AuNPs as the signal amplification platform by our group [103]. In this work, the highly conductive AuNPs were applied as the loading platform of the Mel- $\mathrm{Cu}^{2+}$ tags. The proposed biosensor showed high selectivity, wide linear range and low LOD for target DNA.

Except for the aforementioned amplification strategies, rolling circle amplification (RCA) is one of the most popular and important amplification strategies. Therefore, the dual amplification strategies combined RCA with DNA-AuNPs probe could tremendously improve the sensitivity of bacterial detection. Zhu et al. [104] reported an electrochemical sensing strategy for ultrasensitive and rapid detection of Salmonella by combining the RCA with DNA-AuNPs probe. As shown in Figure 7, the target DNA could be specifically captured by probe 1 on the sensing interface. Then the circularization mixture 


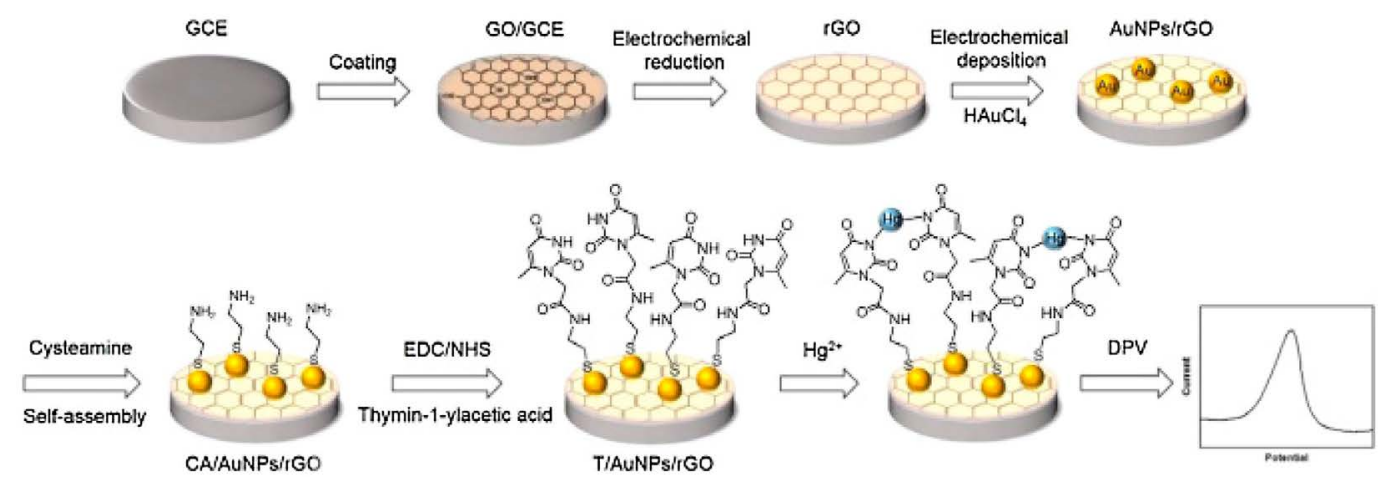

Figure 6. Scheme of thymidine functionalized biosensor for $\mathrm{Hg}^{2+}$ detection. Printed with permission from Wang et al. [94]. Copyright 2016 Elsevier.

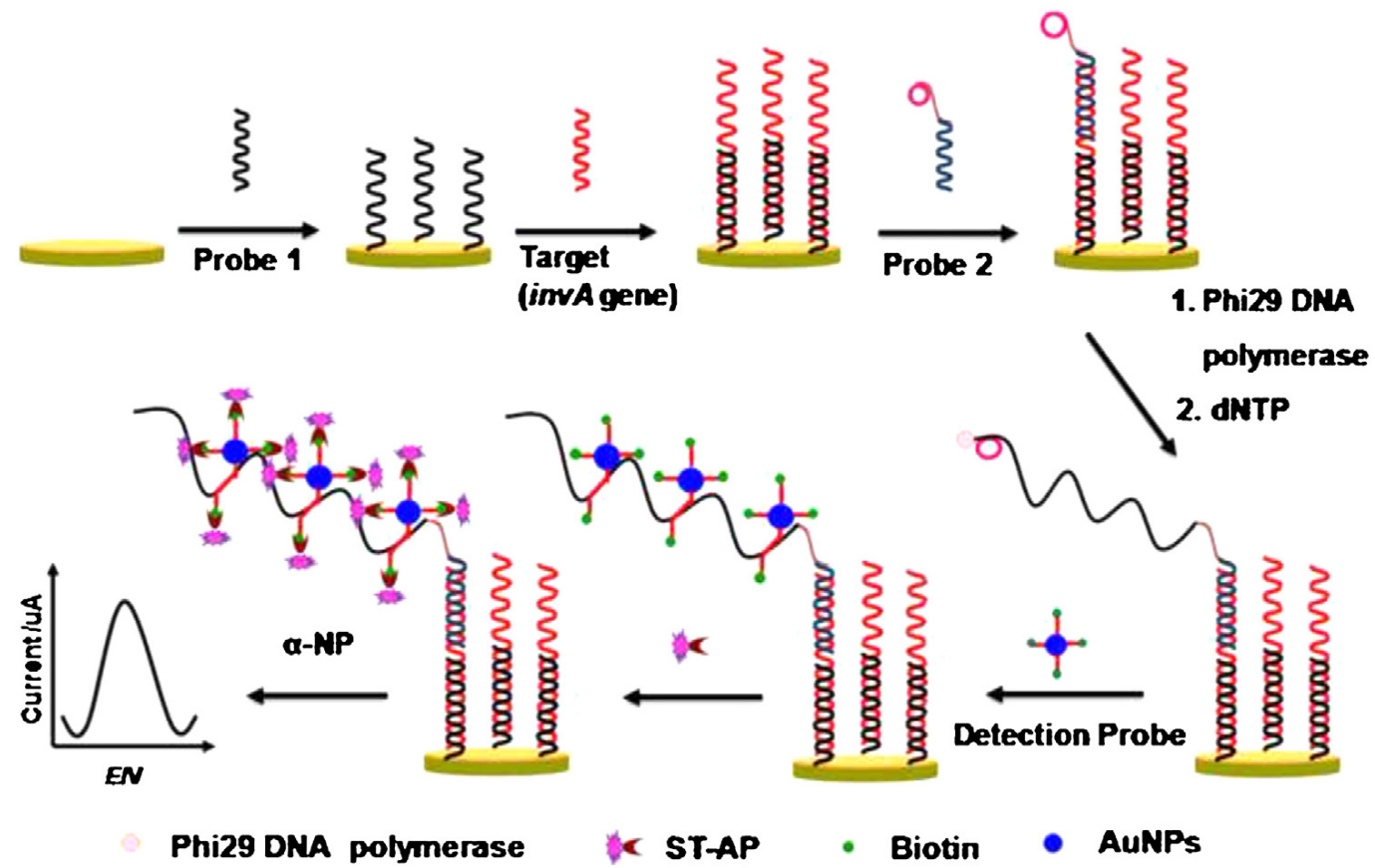

Figure 7. Scheme of the designed strategy for detection of Salmonella. Printed with permission from Zhu et al. [104]. Copyright 2014 Elsevier.

was added to form a typical sandwich structure. In the presence of dNTPs and phi29 DNA polymerase, the RCA was initiated to produce micrometer-long single-strand DNA. Finally, the detection probe (DNA-AuNPs) recognized RCA product to produce enzymatic electrochemical signal. The developed method was successfully applied to detect Salmonella with lower LOD of $6 \mathrm{CFU} \mathrm{mL} \mathrm{m}^{-1}$ in real milk sample.

Both of graphene based materials and AuNPs are the frequently used nanomaterials in the field of EC biosensors for detection of biomolecules due to their excellent electrical signal amplification and the versatile functionalization chemistry. Accordingly, hybrid nanomaterial sensors based on AuNPs distributing on the surface of graphene oxide (GO) or reduce GO (rGO) also attract much scientific interest $[105,106]$. The most frequently used technique refers to reaction of $\mathrm{AuCl}_{3}$ with $\mathrm{GO}$ under reductive condition for in situ anchoring AuNPs to GO or rGO. This method, however, often lacks fine control over the size, uniformity and density of AuNPs on the GO sheets in the reaction process [107]. AuNPs can be decorated to GO surface based on NH-Au binding [108] or SH-Au binding [109]. DNA [110] and proteins [111] have been also used as the molecular linkers between AuNPs and GO. These methods have greatly increased the uniformity and density of AuNPs. Liu et al. [112] presented stable label-free EC sensor for detection of cardiac troponin-I (cTnI) in the early diagnosis of myocardial infarction based on AuNPs and GO nanocomposites. The EC sensor demonstrated good selectivity and high sensitivity against human-cTnI, and was capable of detecting cTnI at concentrations as low as $0.05 \mathrm{ng} \mathrm{mL} \mathrm{L}^{-1}$, which was 100 times lower than that by conventional methods. Karaboga et al. [113] described a simple and disposable immunosensor based on indium-tinoxide (ITO) sheets modified with AuNPs to sensitively analyze heat shock protein70 (HSP70), a potential biomarker that could be evaluated in diagnosis of some carcinomas. Wang et al. [114] constructed an AuNPs/polyaniline/chitosan-graphene sheets based electrochemical DNA sensor with functionalhairpin probe for detection of BCR/ABL fusion gene in chronic myel-ogenous leukemia. Recently, the interest in layered transition metal chalcogenides, especially $\mathrm{MoS}_{2}$, has been growing quickly because they share many impressive physicochemical properties of graphene. Su et al. [115] have prepared an EC sensor based on $\mathrm{MoS}_{2}$ layer for sensitive detection of proteins. In subsequent work, they further fabricated a $\mathrm{MoS}_{2}$ - based EC aptasensor for simultaneous detection of thrombin and adenosine triphosphate (ATP) based on AuNPs- $\mathrm{MoS}_{2}$ nanocomposites [116]. 
Development of novel ultrasensitive EC sensors provides a great opportunity for quick and specific sensing of cancer molecular markers (CMMs), which early detection is of great importance for the success of cancer therapy [117]. Johari-Ahar et al. [118] modified an Au electrode with mercaptopropionic acid (MPA), and then consecutively conjugated with silica coated AuNPs (AuNPs@SiO ${ }_{2}$, CdSe QDs and anti-CA-125 monoclonal antibody (mAb). Successive conjugation of AuNP@SiO, CdSe QD and anti-CA-125 mAb onto the Au electrode resulted in sensitive detection of CA-125 with a LOD of $0.0016 \mathrm{U} \mathrm{mL}^{-1}$. Serafin et al. [119] presented an immuno reagent label-free strategy to construct a dual EC immunosensor using car-bon nanotube screen printed electrodes modified with AuNPs and PEDOT NPs for the multiplexed determination of human growth hormone and prolactin.

The ECL of luminol promoted by AuNMs was reported by Cui $e t$ al. [120]. The ECL intensity of luminol was found to be enhanced by $\sim 2$ to 3 orders with catalysis of AuNPs. Li et al. [121] proposed a simple and sensitive sandwich-type ECL immunosensor for detection of cancer antigen 125 on a nanoporous Au modified glassy carbon electrode. Gao et al. [122] prepared an ultrasensitive luminol ECL immunosensor by using carboxyl group functionalized MWCNTs as platform and glucose oxidase supported on AuNPs decorated MWCNTs as labels. The results indicated that this developed sensor exhibited sensitive and stable response for detection of $\alpha$-1-fetoprotein (AFP), ranging from 0.0001 to $80 \mathrm{ng} \mathrm{mL}^{-1}$ with a LOD down to $0.03 \mathrm{pg} \mathrm{mL}^{-1}$. Gui et al. [123] constructed a simple and sensitive ECL biosensor for determination of $\beta$-lactamase with $\mathrm{Ru}$ (phen) ${ }_{2}$ (cpaphen) ${ }^{2+}$ linked-ampicillin (Ru-Amp). In their work, Ru-Amp complex act not only as a specific recognition element for $\beta$-lactamase but also as the ECL luminescent reagent. The biosensor displayed excellent sensitivity of a concentration variation from $50 \mathrm{pg} \mathrm{mL}^{-1}$ to $100 \mathrm{ng} \mathrm{mL}^{-1}$ with a high sensitivity of $37 \mathrm{pg} \mathrm{mL}^{-1}$. Beside the organic dye, noble metal NPs could greatly affect ECL behavior of semiconductor QDs [124]. The ECL enhancement by LSPR of AuNPs was investigated and termed as surface enhanced ECL (SEECL) [125]. The LSPR of AuNPs was found to increase both the excitation rate and the emission factor of luminophores, and thus the ECL intensity was enhanced greatly. Based on this SEECL effect, a method was developed for ultrasensitive detection of $\mathrm{Hg}^{2+}$ in drinking water [126]. Moreover, a SEECL sensor was prepared for detection of carcinoembryonic antigen (CEA). In this sensor, $\mathrm{Ru}(\mathrm{bpy}){ }_{3}{ }^{2+}$-doped $\mathrm{SiO}_{2} \mathrm{NPs}\left(\mathrm{Ru} @ \mathrm{SiO}_{2}\right)$ act as ECL luminophores, while AuNPs were used as LSPR source to enhance the ECL signal. Two different types of aptamers specific to CEA were modified on the surface of $\mathrm{Ru} @ \mathrm{SiO}_{2}$ and AuNPs, respectively. A LOD of $1.52 \times 10^{-6} \mathrm{ng} / \mathrm{mL}$ of CEA in human serum was achieved [127].

Electrochemical kinase analysis is of special interest in monitoring biological activity in process of life. Measurements of phosphorylation reactions based on oxidation current of electroactive species such as tyrosine [128], ferrocene [129], etc., which are conjugated on the substrate during the phosphorylation processes, have been reported [130]. To simplify the detection procedure, AuNPs labeled phosphorylation process for the kinase assay was designed by measuring the redox currents of AuNPs [131]. However, the sensitivity of the developed method was relatively low. In order to improve the analytical performance, a DNA-based strategy was also described by the chronocoulometric response of $\left[\mathrm{Ru}\left(\mathrm{NH}_{3}\right)_{6}\right]^{3+}$ absorbed on the DNA-AuNPs that linked with the phosphorylated peptide by $\mathrm{Zr}^{4+}$ [132]. Despite the improvement of these methods, it still remains great challenge to develop sensitive, accurate and rapid methods for the profiling of kinase activity and inhibition. Most recently, Wang et al. [133] built a highly sensitive EC sensor for monitoring kinase activity based on DNA induced AuNPs polymeric network block signal amplification. In this strategy, the current signal of EC sensor was significantly amplified to afford a highly sensitive electrochemical analysis of kinase activity, due to its excellent electro activity and high accommodation of the DNA AuNPs polymeric network block for $\left[\mathrm{Ru}\left(\mathrm{NH}_{3}\right)_{6}\right]^{3+}$. Notably, the proposed EC sensor presented a low LOD of $0.03 \mathrm{U} \mathrm{mL}^{-1}$ for protein kinase A (PKA) activity and excellent stability even in cell lysates and serum samples. Jing et al. [134] developed a sensitive and selective electrochemical method for detection of DNA methylationas well as determination of DNA methyltransferase (MTase) activity and screening of MTase inhibitor. In this work, methyleneblue (MB) was employed as electrochemical indicator and DNA-modified AuNPs were used as signal amplification unit because the DNA strands in this composite had strong adsorption ability toward MB (Figure 8). The differential pulse voltammetry signal demonstrated a linear relationship with logarithm of DNA methylation concentration ranging from 0.075 to $30 \mathrm{U} / \mathrm{mL}$, achieving a LOD of $0.02 \mathrm{U} / \mathrm{mL}$.

Overall, the LSPR feature and excellent biocompatibility of AuNMs provide great chance for improving the analytical performance of EC sensors. Currently, only spherical AuNPs have been extensively applied into fabrication of EC sensor. Certainly, other shaped AuNMs possesses specific physiochemical property, and may offer additional application option in signal amplification of ECL or EC sensors.

\section{Conclusion}

1- A series of novel and sophisticated synthesis methods for AuNMs have been developed, but how to precisely control the monodispersed size and morphology and to achieve high quality of AuNMs with vivid color (LSPR) is still a crucial but challengeable issue for their application in analytical science. The AuNMs with preciselycontrolled vivid color possess abundant optical information and can encode biological or chemical recognition units to develop robust analytical methods in food safety, clinic diagnosis and so on. In addition, we are far from controllable assembly of AuNMs into the desirable structures of the collective properties [135].

2- AuNMs have shown excellent performance in enhancement of SERS signal to improve detection sensitivity. Therefore, AuNMs in combination with other functional metal or organic nanomaterials, such as $\mathrm{Si}, \mathrm{Al}, \mathrm{MOF}$ and so on, to develop multimodal composite nanomaterials become a new trend in high sensitive SERS detection of various target analytes [136,137], as well as in high resolution bioimaging in the future.

3- AuNMs offer a rapid, efficient, cost-effective and robust sensing platform for detection of different chemicals and bio-markers due to their unique chemical, physical and optical properties. It is noted that the sensitive, stable and multiplex assay of target analytes is highly desirable. To meet these requirements, new multifunctional AuNMs must be developed and used as LFICA label, colorimetric sensing readout and signal amplification of EC sensor, etc.

4- AuNCs as excellent fluorescent probe materials have shown great potential in analytical science [138]. However, extensive efforts must be made for developing novel synthesis methods to achieve high quality AuNCs with remarkable QY and extraordinary stability. In addition, the coordination nature of the AuNCs-protection group complexes implies that the stability of metal NCs is affected by the presence of other strong competing ligands in aqueous solution. The intracellular stability of AuNCs hence becomes a serious issue. With 


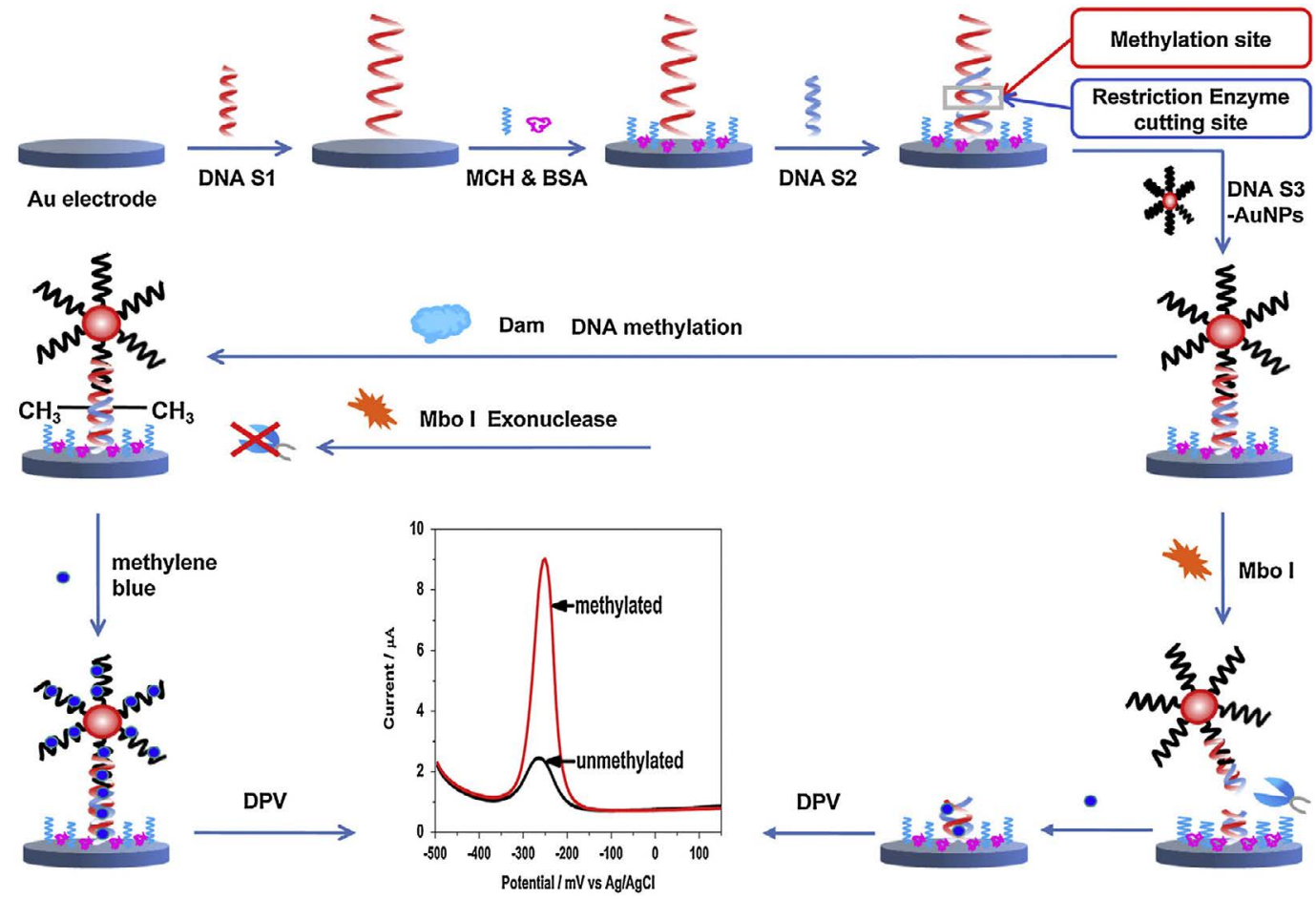

Figure 8. Scheme of the developed method for detection of DNA methylation and assay of DNA methyltransferase activity. Printed with permission from Jing et al. [134]. Copyright 2014 Elsevier.

development of technologies of synthesis and surface modification, AuNCs will be widely employed as alternatives to conventional fluorophores in analytical science including biosensors, bioimaging and so on.

5- We notice that though many new analytical methods based on AuNMs have been developed in the laboratories, such materials are not used as much in an industrial setting. There must be more scope for these platforms to improve, for example, cost of preparing the AuNMs based sensors, reproducibility of different batches for sensor production, and stability of long-term storage of the AuNMs based sensors, and so on.

6- AuNMs with excellent features have prompted great development of analytical sciences and have stood at a critical juncture, with a vast amount of researches that form a solid foundation for future work. Great deals of efforts need to be paid to push on to take AuNMsbased analytical technologies from lab to market.

\section{References}

1. Sardar R, Funston AM, Mulvaney P, Murray RW (2009) Gold nanoparticles: past, present, and future. Langmuir 25: 13840-13851. [Crossref]

2. Wang P, Sun X, Su X, Wang T (2016) Advancements of molecularly imprinted polymers in the food safety field. Analysts $2: 3540-3553$. [Crossref]

3. Zhang L, Wang E (2014) Metal nanoclusters: new fluorescent probes for sensors and bioimaging. Nano Today 9: 132-157. [Crossref]

4. Ballou S, Goodpaster J, MacCrehan W, Reeder D (2003) Bibliography of NIST Biosystems. Anal Bioanal Chem 376: 1149-1150. [Crossref]

5. Burnworth M, Rowan SJ, Weder C (2007) Fluorescent sensors for the detection of chemical warfare agents. Chem Eur J 13: 7828-7836. [Crossref]

6. Zhang Z, Liu J, Feng T, Yao Y (2013) Generic Lanthanide Fluoroimmunoassay for the Simultaneous Screening of 18 Sulfonamides Using an Engineered Antibody. Environ Sci Technol 47: 454-462. [Crossref]

7. Anker JN, Hall WP, Lyandres O, Shah NC (2008) Biosensing with plasmonic nanosensors. Mater 7: 442-453. [Crossref]
8. Song Y, Xu X, MacRenaris KW, Zhang XQ, Mirkin CA, et al. (2009) Multimodal Gadolinium-Enriched DNA Gold Nanoparticle Conjugates for Cellular Imaging. Angewandte 48: 9143-9147. [Crossref]

9. Qian X, Li J, Nie S (2009) Stimuli-Responsive SERS Nanoparticles: Conformational Control of Plasmonic Coupling and Surface Raman Enhancement. J Am Chem Soc 131: 7540-7541. [Crossref]

10. De PK, Neckers DC (2013) Emission enhancement of a carbazole-based fluorophore on a quantum dot surface. Photochem Photobiol Sci 2. [Crossref]

11. Ipe BI, Yoosaf K, Thomas KG (2006) Functionalized Gold Nanoparticles as Phosphorescent Nanomaterials and Sensors. J Am Chem Soc 128: 1907-1913. [Crossref]

12. Kisailus D, Najarian M, Weaver JC (2005) Functionalized Gold Nanoparticles Mimic Catalytic Activity of a Polysiloxane-Synthesizing Enzyme. Adv Mater 17: 1234-1239. [Crossref]

13. Qian X, Peng XH, Ansari DO, Yin Q (2008) In vivo tumor targeting and spectroscopic detection with surface-enhanced Raman nanoparticle tags. Nat Biotechnol 26: 83-90. [Crossref]

14. Haghighi B, Bozorgzadeh S (2011) Nanoparticle-assisted MALDI-TOF MS combined with seed-layer surface preparation for quantification of small molecules. Anal Chim Acta 697: 90-97. [Crossref]

15. Tang F, Tang DP, Su BL, Huang JX, Qiu B (2011) Gold-nanoparticle-modified polyvinylidene fluoride membranes used for western blotting with high sensitivity. Biosens Bioelectron 26: 3219-3226. [Crossref]

16. Zhu Y, Chandra P, Song KM, Ban C (2012) Label-free detection of kanamycin based on the aptamer-functionalized conducting polymer/gold nanocomposite. Biosens Bioelectron 36: 29-34. [Crossref]

17. Sun X, Li F, Shen G, Huang J, Wang X (2014) Aptasensor based on the synergistic contributions of chitosan-gold nanoparticles, graphene-gold nanoparticles and multiwalled carbon nanotubes-cobalt phthalocyanine nanocomposites for kanamycin detection. Analyst 139: 299-308. [Crossref]

18. Magalhães LM, Segundo MA, Reis S, Lima JLFC (2008) Methodological aspects about in vitro evaluation of antioxidant properties. Anal Chim Acta 613: 1-19. [Crossref]

19. Wang Y, Knoll W, Dostalek J (2012) Bacterial Pathogen Surface Plasmon Resonance Biosensor Advanced by Long Range Surface Plasmons and Magnetic Nanoparticle Assays. Anal Chem 84: 8345-8350. [Crossref] 
20. Yang X, Wang Q, Wang K, Tan W, Li H (2007) Enhanced surface plasmon resonance with the modified catalytic growth of Au nanoparticles. Biosens Bioelectron 22: 11061110. [Crossref]

21. Jung J, Na K, Lee J, Kim KW, Hyun J (2009) Enhanced surface plasmon resonance by Au nanoparticles immobilized on a dielectric $\mathrm{SiO}_{2}$ layer on a gold surface. Anal Chim Acta 651: 91-97. [Crossref]

22. Kimling J, Maier M, Okenve B, Kotaidis V, Ballot H, et al. (2006) Turkevich Method for Gold Nanoparticle Synthesis Revisited. J Phys Chem B 110: 15700-15707. [Crossref]

23. Kumar S, Gandhi KS, Kumar R (2007) Modeling of Formation of Gold Nanoparticles by Citrate Method. Ind Eng Chem Res 46: 3128-3136. [Crossref]

24. Schmid G (1992) Large clusters and colloids. Metals in the embryonic state. Chem Rev 92: 1709-1727. [Crossref]

25. Schmid G, Chi LF (1998) Metal Clusters and Colloids. Adv Mater 10: 515-526. [Crossref]

26. Brust M, Fink J, Bethell D, Schiffrin DJ, Kiely CJ (1995) Synthesis and reactions of functionalised gold nanoparticles. J Chem Soc ChemCommun 16: 1655-1656. [Crossref]

27. Saha K, Agasti SS, Kim C, Li X, Rotello VM (2012) Gold Nanoparticles in Chemical and Biological Sensing. Chem Rev 112: 2739-2779. [Crossref]

28. Daniel MC, Astruc D (2004) Gold Nanoparticles: Assembly, Supramolecular Chemistry, Quantum-Size-Related Properties, and Applications toward Biology, Catalysis, and Nanotechnology. Chem Rev 104: 293-346. [Crossref]

29. Burda C, Chen X, Narayan R, El-Sayed MA (2005) Chemistry and Properties of Nanocrystals of Different Shapes. Chem Rev 105: 1025-1102. [Crossref]

30. Skrabalak SE, Chen J, Au L, Lu X, Li X, et al. (2007) Gold Nanocages for Biomedical Applications. Adv Mater 19: 3177-3184. [Crossref]

31. Sun Y, Xia Y (2002) Shape-Controlled Synthesis of Gold and Silver Nanoparticles. Science 298: 2176-2179. [Crossref]

32. Malikova N, Pastoriza-Santos I, Schierhorn M, Kotov NA, Liz-Marzan LM (2002) Layer-by-Layer Assembled Mixed Spherical and Planar Gold Nanoparticles: Control of Interparticle Interactions 18: 3694-3697. [Crossref]

33. Manna L, Milliron D, Meisel A, Scher EC, Alivisatos AP (2003) Controlled growth of tetrapod-branched inorganic nanocrystals. Nat Mater 2: 382-385. [Crossref]

34. Cao YW, Jin R, Mirkin CA (2001) DNA-Modified Core-Shell Ag/Au Nanoparticles. $J$ Am Chem Soc 123: 7961-7962. [Crossref]

35. Zhang L, Niu W, Xu G (2012) Synthesis and applications of noble metal nanocrystals with high-energy facets. Nano Today 7: 586-605. [Crossref]

36. Lai J, Niu W, Luque R, Xu G (2015) Solvothermal synthesis of metal nanocrystals and their applications. Nano Today 10: 240-267. [Crossref]

37. Kim F, Song JH, Yang P (2002) Photochemical Synthesis of Gold Nanorods. J Am Chem Soc 124: 14316-14317. [Crossref]

38. Niu W, Zheng S, Wang D, Liu X, Li H, et al. (2009) Selective Synthesis of SingleCrystalline Rhombic Dodecahedral, Octahedral, and Cubic Gold Nanocrystals. J Am Chem Soc 131: 697-703. [Crossref]

39. Niu W, Chua YAA, Zhang W, Huang H, Lu X (2015) Highly Symmetric Gold Nanostars: Crystallographic Control and Surface-Enhanced Raman Scattering Property. J Am Chem Soc 137: 10460-10463. [Crossref]

40. Zheng J, Petty JT, Dickson RM (2003) High Quantum Yield Blue Emission from Water-Soluble Au8 Nanodots. J Am Chem Soc 125: 7780-7781. [Crossref]

41. Xie J, Zheng Y, Ying JY (2009) Protein-Directed Synthesis of Highly Fluorescent Gold Nanoclusters. J Am Chem Soc 131: 888-889. [Crossref]

42. Varnavski O, Ramakrishna G, Kim J, Lee D, Goodson T (2010) Critical Size for the Observation of Quantum Confinement in Optically Excited Gold Clusters. J Am Chem Soc 132: 16-17. [Crossref]

43. Tang Z, Xu B, Wu B, Germann MW, Wang G (2010) Synthesis and Structural Determination of Multidentate 2,3-Dithiol-Stabilized Au Clusters. J Am Chem Soc 132: 3367-3374. [Crossref]

44. Yu Y, Luo Z, Chevrier DM, Leong DT, Zhang P, et al. (2014) Identification of a Highly Luminescent $\mathrm{Au}_{22}(\mathrm{SG})_{18}$ Nanocluster. J Am Chem Soc 136: 1246-1249. [Crossref]

45. Pyo K, Thanthirige VD, Kwak K, Pandurangan P, Ramakrishna G, et al. (2015) Ultrabright Luminescence from Gold Nanoclusters: Rigidifying the $\mathrm{Au}(\mathrm{I})$-Thiolate Shell. J Am Chem Soc 137: 8244-8250. [Crossref]
46. Tan LH, Xing H, Lu Y (2014) DNA as a Powerful Tool for Morphology Control, Spatial Positioning, and Dynamic Assembly of Nanoparticles. Acc Chem Res 47: 1881-1890. [Crossref]

47. Wang Z, Tang L, Tan LH, Li J, Lu Y (2012) Discovery of the DNA "Genetic Code" for Abiological Gold Nanoparticle Morphologies. Angew Chem Int Ed 51: 9078-9082. [Crossref]

48. Song T, Tang L, Tan LH, Wang X, Satyavolu NSR, et al. (2015) DNA-Encoded Tuning of Geometric and Plasmonic Properties of Nanoparticles Growing from Gold Nanorod Seeds. Angew Chem Int Ed 54: 8114-8118. [Crossref]

49. Tan LH, Yue Y, Satyavolu NSR, Ali AS, Wang Z, et al. (2015) Mechanistic Insigh into DNA-Guided Control of Nanoparticle Morphologies. J Am Chem Soc 137: 1445614464. [Crossref]

50. Ye X, Jin L, Cagalayan H, Chen J, Xing G, (2012) Improved Size-Tunable Synthesis of Monodisperse Gold Nanorods through the Use of Aromatic Additives. ACS Nano 6: 2804-2817. [Crossref]

51. Krishna KS, Navin CV, Biswas S, Singh V, Ham K, et al. (2013) Millifluidics for Timeresolved Mapping of the Growth of Gold Nanostructures. J Am Chem Soc 135: 54505456. [Crossref]

52. Johnston CW, Wyatt MA, Li X, Ibrahim A, Shuster J, et al. (2013) Gold biomineralization by a metallophore from a gold-associated microbe. Nat Chem Biol 9: 241-243. [Crossref]

53. Zhang MX, Cui R, Tian ZQ, Zhang ZL, Pang DW (2010) Kinetics-Controlled Formation of Gold Clusters Using a Quasi-Biological System. Adv Funct Mater 20: 3673-3677. [Crossref]

54. Shin Y, Lee C, Yang MS, Jeong S, Kim D, et al. (2014) Two-dimensional Hyperbranched Gold Nanoparticles Synthesized on a Two-dimensional Oil/Water Interface. Sci Rep 4: 6119. [Crossref]

55. Abdelaziz R, Disci-Zayed D, Hedayati MK, Pohls JH, Zillohu AU, et al. (2013) Green chemistry and nanofabrication in a levitated Leidenfrost drop. Nat Com 4: 2400. [Crossref]

56. Kim JH, Twaddle KM, Hu J, Byun H (2014) Sunlight-Induced Synthesis of Various Gold Nanoparticles and Their Heterogeneous Catalytic Properties on a Paper-Based Substrate. ACS Appl Mater Interfaces 6: 11514-11522. [Crossref]

57. Gao C, Zhang Q, Lu Z, Yin Y (2011) Templated Synthesis of Metal Nanorods in Silica Nanotubes. J Am Chem Soc 133: 19706-19709. [Crossref]

58. Liu J, Qiao S, Hartono SB, Lu G, (2010) Monodisperse Yolk-Shell Nanoparticles with a Hierarchical Porous Structure for Delivery Vehicles and Nanoreactors. Angew Chem Int Ed 49: 4981-4985. [Crossref]

59. Christesen SD (1988) Raman Cross Sections of Chemical Agents and Simulants. Appl Spectrosc 42: 318-321. [Crossref]

60. Yan J, Su S, He S, He Y, Zhao B, et al. (2012) Nano Rolling-Circle Amplification for Enhanced SERS Hot Spots in Protein Microarray Analysis. Anal Chem 84: 9139-9145. [Crossref]

61. Li M, Cushing SK, Zhang J, Suri S, Evans R, et al. (2013) Three-Dimensional Hierarchical Plasmonic Nano-Architecture Enhanced Surface-Enhanced Raman Scattering Immunosensor for Cancer Biomarker Detection in Blood Plasma. ACS Nano 7: 4967-4976. [Crossref]

62. Luo Z, Li W, Lu D, Chen K, He Q, et al. (2013) A SERS-based immunoassay for porcine circovirus type 2 using multi-branched gold nanoparticles. Microchim. Acta 180: 1501-1507. [Crossref]

63. Tang J, Sun J, Lui R, Zhang Z, Liu J, et al. (2016) New Surface-Enhanced Raman Sensing Chip Designed for On-Site Detection of Active Ricin in Complex Matrices Based on Specific Depurination. ACS Appl Mater Interfaces 8: 2449-2455. [Crossref]

64. Qian XM, Peng XH, Ansari DO, Yin-Goen Q, Chen GZ, et al. (2008) In vivo tumor targeting and spectroscopic detection with surface-enhanced Raman nanoparticle tag. Nat Biotechnol 26: 83-90. [Crossref]

65. Lim DK, Jeon KS, Kim HM, Nam JM, Suh YD (2010) Nanogap-engineerable Ramanactive nanodumbbells for single-molecule detection. Nat Mater 9: 60-67. [Crossref]

66. Wang Y, Zhang CH, Tang LJ, Jiang JH (2012) Enzymatic Control of Plasmonic Coupling and Surface Enhanced Raman Scattering Transduction for Sensitive Detection of DNA Demethylation. Anal Chem 84: 8602-8606. [Crossref]

67. Seydack M (2005) Nanoparticle labels in immunosensing using optical detection methods. Biosens Bioelectron 20: 2454-2469. [Crossref] 
68. Chen K, Han H, Luo Z, Wang Y, Wang X (2012) A practicable detection system for genetically modified rice by SERS-barcoded nanosensors. Biosens Bioelectron 34: 118 124. [Crossref]

69. Ye S, Wu Y, Zhai X, Tang B (2015) Asymmetric Signal Amplification for Simultaneous SERS Detection of Multiple Cancer Markers with Significantly Different Levels. Anal Chem 87: 8242-8249. [Crossref]

70. Wen CY, Wu LL, Zhang ZL, Liu YL, Wei SZ, et al. (2014) Quick-Response Magnetic Nanospheres for Rapid, Efficient Capture and Sensitive Detection of Circulating Tumor Cells. ACS Nan 8: 941-949. [Crossref]

71. Wang X, Qian XM, Beitler JJ, Chen ZG, Khuri FR, et al. (2011) Detection of Circulating Tumor Cells in Human Peripheral Blood Using Surface-Enhanced Raman Scattering Nanoparticles. Cancer Res 71: 1526-1532. [Crossref]

72. Wu X, Luo L, Yang S, Ma X, Li Y, et al. (2015) Improved SERS Nanoparticles for Direct Detection of Circulating Tumor Cells in the Blood. ACS Appl Mater Interfaces 7: 9965-9971. [Crossref]

73. Dudak FC, Boyacı IH (2009) Rapid and label-free bacteria detection by surface plasmon resonance (SPR) biosensors. Biotechnol J 4: 1003-1011. [Crossref]

74. Ashley J, Li SFY (2013) An aptamer based surface plasmon resonance biosensor for the detection of bovine catalase in milk. Biosens Bioelectron 48: 126-131. [Crossref]

75. McPhillips J, Murphy A, Jonsson MP, Hendren WR, Atkinson R, et al. (2010) HighPerformance Biosensing Using Arrays of Plasmonic Nanotubes. A C S Nano 4: 22102216. [Crossref]

76. Sim HR, Wark AW, Lee HJ (2010) Attomolar detection of protein biomarkers using biofunctionalized gold nanorods with surface plasmon resonance. Analyst 135: 25282532. [Crossref]

77. Shankaran DR, Gobi KV, Miura N (2007) Recent advancements in surface plasmon resonance immunosensors for detection of small molecules of biomedical, food and environmental interest. Sens Actuators B Chem 121: 158-177. [Crossref]

78. Fernandez F, Sanchez-Baeza F, Marco MP (2012) Nanogold probe enhanced Surface Plasmon Resonance immunosensor for improved detection of antibiotic residues. Biosens Bioelectron 34: 151-158. [Crossref]

79. Jung J, Na K, Lee J, Kimb KW, Hyun J (2009) Enhanced surface plasmon resonance by $\mathrm{Au}$ nanoparticles immobilized on a dielectric $\mathrm{SiO}^{2}$ layer on a gold surface. Anal Chim Acta 651: 91-97. [Crossref]

80. Ko S, Park TJ, Kim HS, Kim JH, Cho YJ (2009) Directed self-assembly of gold binding polypeptide-protein A fusion proteins for development of gold nanoparticle-based SPR immunosensors. Biosens Bioelectron 24: 2592-2597. [Crossref]

81. Wang JL, Munir A, Li ZH, Zhou HS (2009) Aptamer-Au NPs conjugates-enhanced SPR sensing for the ultrasensitive sandwich immunoassay. Biosens Bioelectron 25: 124-129. [Crossref]

82. Xu S, Shang MY, Liu GX, Xu F, Wang X (2013) Chemical Constituents from the Rhizomes of Smilax glabra and Their Antimicrobial Activity. Molecules 18: 52655287. [Crossref]

83. Law WC, Yong KT, Baev A, Prasad AN (2011) Sensitivity Improved Surface Plasmon Resonance Biosensor for Cancer Biomarker Detection Based on Plasmonic Enhancement. ACS Nano 5: 4858-4864. [Crossref]

84. Xiang Y, Zhu X, Huang Q, Zheng J, Fu W (2015) Real-time monitoring of mycobacterium genomic DNA with target-primed rolling circle amplification by a $\mathrm{Au}$ nanoparticle-embedded SPR biosensor. Biosens. Bioelectron 66: 512-519. [Crossref]

85. Li XS, Cai WW, An J, Kim S, Nah J, et al. (2009) Large-Area Synthesis of High-Quality and Uniform Graphene Films on Copper Foils. Science 324: 1312-1314. [Crossref]

86. Shang JZ, Ma L, Li JW, Ai W, Yu T (2012) The Origin of Fluorescence from Graphene Oxide. Sci Rep 2: 792-799. [Crossref]

87. Zhang J, Sun Y, Wu Q, Zhang H, Bai Y, et al. A protein A modified Au-graphene oxide composite as an enhanced sensing platform for SPR-based immunoassay. Analyst 138: 7175-7181. [Crossref]

88. Xie C, Li H, Li S, Wu J, Zhang Z (2010) Surface Molecular Self-Assembly for Organophosphate Pesticide Imprinting in Electropolymerized Poly(p-aminothiophenol) Membranes on a Gold Nanoparticle Modified Glassy Carbon Electrode. Anal Chem 82: 241-249. [Crossref]

89. Yu D, Zeng Y, Qi Y, Zhou T, Shi G (2012) A novel electrochemical sensor for determination of dopamine based on AuNPs@SiO2 core-shell imprinted composite. Biosens Bioelectron 38: 270-277. [Crossref]
90. Xue C, Han Q, Wang Y, Wu J, Wen T, et al. (2013) Amperometric detection of dopamine in human serumby electrochemical sensor based on gold nanoparticles doped molecularly imprinted polymers. Biosens Bioelectron 49: 199-203. [Crossref]

91. Sun XL, Zhang LJ, Zhang HX, Qian H, Zhang YZ, et al. (2014) Development and Application of 3-Chloro-1,2-propandiol Electrochemical Sensor Based on a Polyaminothiophenol Modified Molecularly Imprinted Film. J Agric Food Chem 62: 4552-4557. [Crossref]

92. Shen L, Chen Z, Li YH, He SL, Xie SB, et al. (2008) Electrochemical DNAzyme Sensor for Lead Based on Amplification of DNA-Au Bio-Bar Codes. Anal Chem 80: 6323-6328. [Crossref]

93. Tang S, Tong P, Lu W, Chen JF, Yan ZM, et al. (2014) A novel label-free electrochemica sensor for $\mathrm{Hg} 2+$ based on the catalytic formation of metal nanoparticle. Biosens Bioelectron 59: 1-5. [Crossref]

94. Wang N, Lin M, Dai H, Ma H (2016) Functionalized gold nanoparticles/reduced graphene oxide nanocomposites for ultrasensitive electrochemical sensing of mercury ions based on thymine-mercury-thymine structure. Biosens Bioelectron 79: 320-326. [Crossref]

95. Wang S, Wang Y, Zhou L, Li J, Wang S, et al. (2014) Fabrication of an effective electrochemical platform based on graphene and AuNPs for high sensitive detection of trace $\mathrm{Cu}^{2+}$. Electrochim Acta 132: 7-14. [Crossref]

96. Yang Y, Zhang S, Kang M, He L, Zhao J, et al. (2015) Selective detection of silver ions using mushroom-like polyaniline and gold nanoparticle nanocomposite-based electrochemical DNA sensor. Anal Biochem 490: 7-13. [Crossref]

97. Lu Y, Zhu N, Yu P, Mao L Aptamer-based electrochemical sensors that are not based on the target binding-induced conformational change of aptamers. Analyst 133: 12561260. [Crossref]

98. Xiao Y, Piorek BD, Plaxco KW, Heeger AJ A Reagentless Signal-On Architecture for Electronic, Aptamer-Based Sensors via Target-Induced Strand Displacement. J Am Chem Soc 127: 17990-17991. [Crossref]

99. Mao X, Ma Y, Zhang A, Zhang L, Zeng L, et al. X. Mao, Y. Ma, A. Zhang, L. Zhang, L. Zeng, G. Liu, Anal. Chem. 81 (2009)1660-1668. Anal Chem 81: 1660-1668. [Crossref]

100. Zheng J, Feng W, Lin L, Zhang F, Cheng G, et al. (2007) A new amplification strategy for ultrasensitive electrochemical aptasensor with network-like thiocyanuric acid gold nanoparticles. Biosens Bioelectron 23: 341-347. [Crossref]

101. Zhao J, Zhang Y, Li H, Wen Y, Fan X, et al. (2011) Ultrasensitive electrochemical aptasensor for thrombin based on the amplification of aptamer-AuNPs-HRP conjugates. Biosens Bioelectron 26: 2297-2303. [Crossref]

102. He X, Su J, Wang Y, Wang K, Ni X, et al. (2011) A sensitive signal-on electrochemica assay for MTase activity using AuNPs amplification. Biosens Bioelectron 28: 298303. [Crossref]

103. Wang Q, Gao F, Ni1 J, Liao X, Zhang X, et al. (2016) Facile construction of a highly sensitive DNA biosensor by in-situ assembly of electro-active tags on hairpinstructured probe fragment. Sci Rep 6: 22441. [Crossref]

104. Zhu D, Yan Y, Lei P, Shen B, Cheng W, et al. (2014) A novel electrochemical sensing strategy for rapid and ultrasensitive detection of Salmonella by rolling circle amplification and DNA-AuNPs probe. Anal Chim Acta 846: 44-50. [Crossref]

105. Song W, Li DW, Li YT, Li Y, Long YT (2011) Disposable biosensor based on graphene oxide conjugated with tyrosinase assembled gold nanoparticles. Biosens Bioelectron 26: 3181-3186. [Crossref]

106. Li C, Wei L, Liu X, Lei L, Li G (2014) Anal Chim Acta 831: 60e64. [Crossref]

107. Myung S, Park J, Lee H, Kim KS, Hong S (2010) Ambipolar Memory Devices Based on Reduced Graphene Oxide and Nanoparticles. Adv Mater 22: 2045-2049. [Crossref]

108. Huang KJ, Niu DJ, Liu X, Wu ZW, Fan Y, et al. (2011) Direct electrochemistry of catalase at amine-functionalized graphene/gold nanoparticles composite film for hydrogen peroxide sensor. Electrochim Acta 56: 2947-2953. [Crossref]

109. Cui P, Seo S, Lee J, Wang L, Lee E, et al. (2011) Nonvolatile Memory Device Using Gold Nanoparticles Covalently Bound to Reduced Graphene Oxide. ACS Nano 5: 6826-6833. [Crossref]

110. Zheng J, He Y, Sheng Q, Zhang H (2011) DNA as a linker for biocatalytic deposition of Au nanoparticles on graphene and its application in glucose detection. $J$ Mater Chem 21: 12873-12879. [Crossref]

111. Liu J, Fu S, Yuan B, Li Y, Deng Z (2010) Toward a Universal "Adhesive Nanosheet" for the Assembly of Multiple Nanoparticles Based on a Protein-Induced Reduction/ Decoration of Graphene Oxide. J Am Chem Soc 132: 7279-7281. [Crossref] 
112. Liu G, Qi M, Zhang Y, Cao C, Goldys EM (2016) Nanocomposites of gold nanoparticles and graphene oxide towards an stable label-free electrochemical immunosensor for detection of cardiac marker troponin-I. Anal Chim Acta 909: 1-8. [Crossref]

113. Karaboga MNS, Simsek CS, Sezgintürk MK (2016) AuNPs modified, disposable, ITO based biosensor: Early diagnosis of heat shock protein 70. Biosens Bioelectron 84: 22-29. [Crossref]

114. Wang L, Hua E, Liang M, Ma C, Liu Z, et al. (2014) Graphene sheets, polyaniline and AuNPs based DNA sensor for electrochemical determination of BCR/ABL fusion gene with functional hairpin probe. Biosens Bioelectron 51: 201-207. [Crossref]

115. Su S, Zou M, Zhao H, Yuan C, Xu Y, et al. (2015) Shape-controlled gold nanoparticles supported on MoS2 nanosheets: synergistic effect of thionine and MoS2 and their application for electrochemical label-free immunosensing. Nanoscale 7: 1912919135. [Crossref]

116. Su S, Sun H, Cao W, Chao J, Peng H, et al. (2016) Dual-Target Electrochemical Biosensing Based on DNA Structural Switching on Gold Nanoparticle-Decorated MoS2 Nanosheets. ACSAppl. Mater Interfaces 8: 6826-6833. [Crossref]

117. Das J, Kelley SO (2011) Protein Detection Using Arrayed Microsensor Chips: Tuning Sensor Footprint to Achieve Ultrasensitive Readout of CA-125 in Serum and Whole Blood. Anal Chem 83: 1167-1172. [Crossref]

118. Johari-Ahar M, Rashidi MR, Barar J, Aghaie M, Mohammadnejad D, et al. (2015) An ultra-sensitive impedimetric immunosensor for detection of the serum oncomarker CA-125 in ovarian cancer patients. Nanoscale 7: 3768-3779. [Crossref]

119. Serafin V, Martinez-Garcia G, Agui L, Ynez-Sedeno P, Pingarron JM (2014) Multiplexed determination of human growth hormone and prolactin at a label free electrochemical immunosensor using dual carbon nanotube-screen printed electrodes modified with gold and PEDOT nanoparticles. Analyst 139: 4556-4563. [Crossref]

120. Cui C, Xu Y, Zhang ZF (2004) Multichannel Electrochemiluminescence of Luminol in Neutral and Alkaline Aqueous Solutions on a Gold Nanoparticle Self-Assembled Electrode. Anal Chem 76: 4002-4010. [Crossref]

121. Li M, Zhang M, Ge S, Yan M, Yu J, (2013) Ultrasensitive electrochemiluminescence immunosensor based on nanoporous gold electrode and Ru-AuNPs/graphene as signal labels. Sens Actuators B 181: 50-56. [Crossref]

122. Cao Y, Yuan R, Chai Y, Mao L, Niu H, et al. (2012) Ultrasensitive luminol electrochemiluminescence for protein detection based on in situ generated hydrogen peroxide as coreactant with glucose oxidase anchored AuNPs@MWCNTs labeling. Biosens Bioelectron 31: 305-309. [Crossref]

123. Gui GF, Zhuo Y, Chai YQ, Xiang Y, Yuan R (2015) A novel ECL biosensor for $\beta$-lactamase detection: Using RU(II) linked-ampicillin complex as the recognition element. Biosens Bioelectron 70: 221-225. [Crossref]
124. Wang J, Shan Y, Zhao WW, Xu JJ, Chen HY (2011) Gold Nanoparticle Enhanced Electrochemiluminescence of CdS Thin Films for Ultrasensitive Thrombin Detection. Anal Chem 83: 4004-4011. [Crossref]

125. Wang D, Guo L, Huang R, Qiu B, Lin Z, et al. (2015) Surface Enhanced Electrochemiluminescence of Ru(bpy) ${ }_{3}^{2+}$. Sci Rep 5: 7954. [Crossref]

126. Wang D, Guo L, Huang R, Qiu B, Lin Z, et al. (2014) Surface Enhanced Electrochemiluminescence for Ultrasensitive Detection of $\mathrm{Hg}^{2+}$. Electrochim Acto 150: 123-128. [Crossref]

127. Wang D,LiY,LinZ, QiuB, GuoL(2015) Surface-EnhancedElectrochemiluminescence of Ru@SiO for Ultrasensitive Detection of Carcinoembryonic Antigen. Anal Chem 87: 5966-5972. [Crossref]

128. Kerman K, Vestergaard MD, Tamiya E (2007) Label-Free Electrical Sensing of Small-Molecule Inhibition on Tyrosine Phosphorylation. Anal Chem 79: 6881-6885. [Crossref]

129. Wilkins MHF, Stokes AR, Wilson HR (1953) Molecular structure of nucleic acids molecular structure of deoxypentose nucleic acids. Nature 171: 738-740. [Crossref]

130. Sessler JL, Lawrence CM, Jayawickramarajah J (2007) Molecular recognition via base-pairing. Chem Soc Rev 36: 314-325. [Crossref]

131. Kerman K, Chikae M, Yamamura S, Tamiya S (2007) Gold nanoparticle-based electrochemical detection of protein phosphorylation. Anal Chim Acta 588: 26-33. [Crossref]

132. Liu X, Du J, Li C, Han X, Hu X, et al. (2015) The anion effect on the oxygen reduction of $\mathrm{MnX}(\mathrm{X}=\mathrm{O}, \mathrm{S}$, and $\mathrm{Se})$ catalysts. Journal of Materials Chemistry A 7 : 3425-3431. [Crossref]

133. Wang Z, Sun N, He Y, Liu Y, Li J (2014) DNA Assembled Gold Nanoparticles Polymeric Network Blocks Modular Highly Sensitive Electrochemical Biosensors for Protein Kinase Activity Analysis and Inhibition. Anal Chem 86: 6153-6159. [Crossref]

134. Jing X, Cao X, Wang L, Lan T, Li Y, et al. (2014) DNA-AuNPs based signal amplification for highly sensitive detection of DNA methylation, methyltransferase activity and inhibitor screening. Biosens Bioelectron 58: 40-47. [Crossref]

135. Srivastava S, Santos A, Critchley K, Kim KS, Podsiadlo P, et al. (2010) LightControlled Self-Assembly of Semiconductor Nanoparticles into Twisted Ribbons. Science 327: 1355-1359. [Crossref]

136. Wang P, Lin Z, Su X, Tang Z (2017) Application of Au based nanomaterials in analytical science. Nano Today 12: 64-97. [Crossref]

137. Wu DY, Li JF, Ren B, Tian ZQ (2008) Electrochemical surface-enhanced Raman spectroscopy of nanostructures. Chem Soc Rev 37: 1025-1041.

138. Shang L, Dong SJ, Ulrich Nienhaus G (2011) Ultra-small fluorescent metal nanoclusters Synthesis and biological applications. Nano Today 6: 401-418. [Crossref]

Copyright: $\odot 2017$ Madkour LH. This is an open-access article distributed under the terms of the Creative Commons Attribution License, which permits unrestricted use, distribution, and reproduction in any medium, provided the original author and source are credited. 